\title{
IDENTIFICACIÓN TAXONÓMICA DE FRAGMENTOS DE MADERA DE LOS FÉRETROS DE LA NECRÓPOLIS TARDORROMANA DE SENDA DE GRANADA (MURCIA)
}

\author{
TAXONOMIC IDENTIFICATION OF WOOD FRAGMENTS FROM THE WOODEN COFFINS FOUND IN \\ THE LATE ROMAN NECROPOLIS OF SENDA DE GRANADA (MURCIA)
}

\author{
MARÍA SOLEDAD GARCÍA MARTÍNEZ \\ Universidad de Murcia \\ LUIS ALBERTO GARCÍA BLÁNQUEZ \\ ArqueoTec
}

\section{INTRODUCCIÓN}

Los contextos funerarios de cualquier época constituyen valiosas fuentes de información socio-cultural acerca de las prácticas y ritos de una determinada comunidad. En el caso de las necrópolis de inhumación, los restos óseos, la indumentaria, los ajuares o la arquitectura funeraria son los aspectos más comúnmente estudiados para lograr esta información. El análisis de otros elementos integrantes de estos contextos, como los féretros o parihuelas de madera, ha sido, sin embargo, escasamente abordado. Esto es debido a que la preservación de los materiales orgánicos frescos resulta excepcional, estando normalmente ligada a condiciones anaerobias (Piqué, 2006) o a procesos físico-químicos como la mineralización de los tejidos leñosos (Watson, 1988; Keepax, 1975, 1989). Pese a esta rareza, la información socio-económica que potencialmente pueden ofrecer los féretros es considerable. Se refiere sobre todo a la existencia eventual de procesos selectivos de la madera debido a sus propiedades físico-químicas o al estatus social del inhumado.

En el caso de las necrópolis tardorromanas, la conservación de restos de madera gracias a la oxidación de los clavos que unieron los tablones del féretro no es un hecho aislado (Hernández García, 1998; Iniesta Sanmartín y Martínez Alcalde, 2000; García Blánquez, 2010). Esta preservación es un proceso que acontece debido a que la corrosión produce sales que protegen la materia orgánica, conservando su estructura microscópica. Para que así ocurra, la madera debe estar en contacto con el metal (Badal et alii, 2007; Moskal y Badal, 2008), cuya oxidación provoca la migración de óxidos de hierro a la estructura leñosa, antes de que se produzca su degradación por acción de microorganismos (Watson, 1988). En la mayoría de casos es posible observar la estructura microscópica e identificar taxonómicamente dicha madera mediante la observación con microscopio de luz reflejada. Cuando esto no es posible, pueden ser utilizadas otras técnicas como la visualización tridimensional por microtomografía de rayos X (Bird et alii, 2008; Haneca et alii, 2011).

Pese al indudable interés que ofrecen los restos de madera hallados en inhumaciones, los trabajos publicados hasta el momento son escasos y de gran dispersión cronológica y espacial (Salin, 1952; Bartholin, 1978; Pétrequin et alii, 1980; Hirst et alii, 1983; Soulier, 1988; Maspero, 1989; Rollier, 1992; citados en Hunot, 1996; Bouchaud et alii, 2009). De ahí la gran relevancia de este estudio, que aporta los primeros datos conocidos para todo el ámbito peninsular en lo que concierne a la madera empleada para la elaboración de féretros o parihuelas en una necrópolis tardorromana. Abordaremos concretamente la identificación taxonómica de los restos de madera mineralizada adherida a los clavos metálicos documentados en algunas de las sepulturas halladas en un edificio de culto de la necrópolis de Senda de Granada (Murcia) (sector E1). A través de su identificación será posible realizar consideraciones relativas a las zonas de adquisición de dicha madera o a la posible existencia de relaciones entre la selección de la misma y el estatus social de los individuos inhumados en este grupo de tumbas.

\section{LA SENDA DE GRANADA. LOCALIZACIÓN Y CONTEXTO ARQUEOLÓGICO}

El yacimiento de Senda de Granada (García Blánquez, 2010) se encuentra a $2,6 \mathrm{~km}$ al noroeste de la ciudad de Murcia (Fig. 1), en una antigua zona de huerta atravesada actualmente por dos acequias de riego medievales (Alfatego, al sur y Churra La Vieja, por el norte).

Las instalaciones romanas ocuparon parte de un antiguo abanico aluvial modelado por la erosión remontante, en el que se había conformado un relieve de pequeñas lomas amesetadas de escasa altura, surcadas por vaguadas intermedias con una planicie levemente inclinada hacia el sureste. En este paisaje, los altozanos fueron aprovechados para ubicar algunas construcciones y las instalaciones productivas. En 


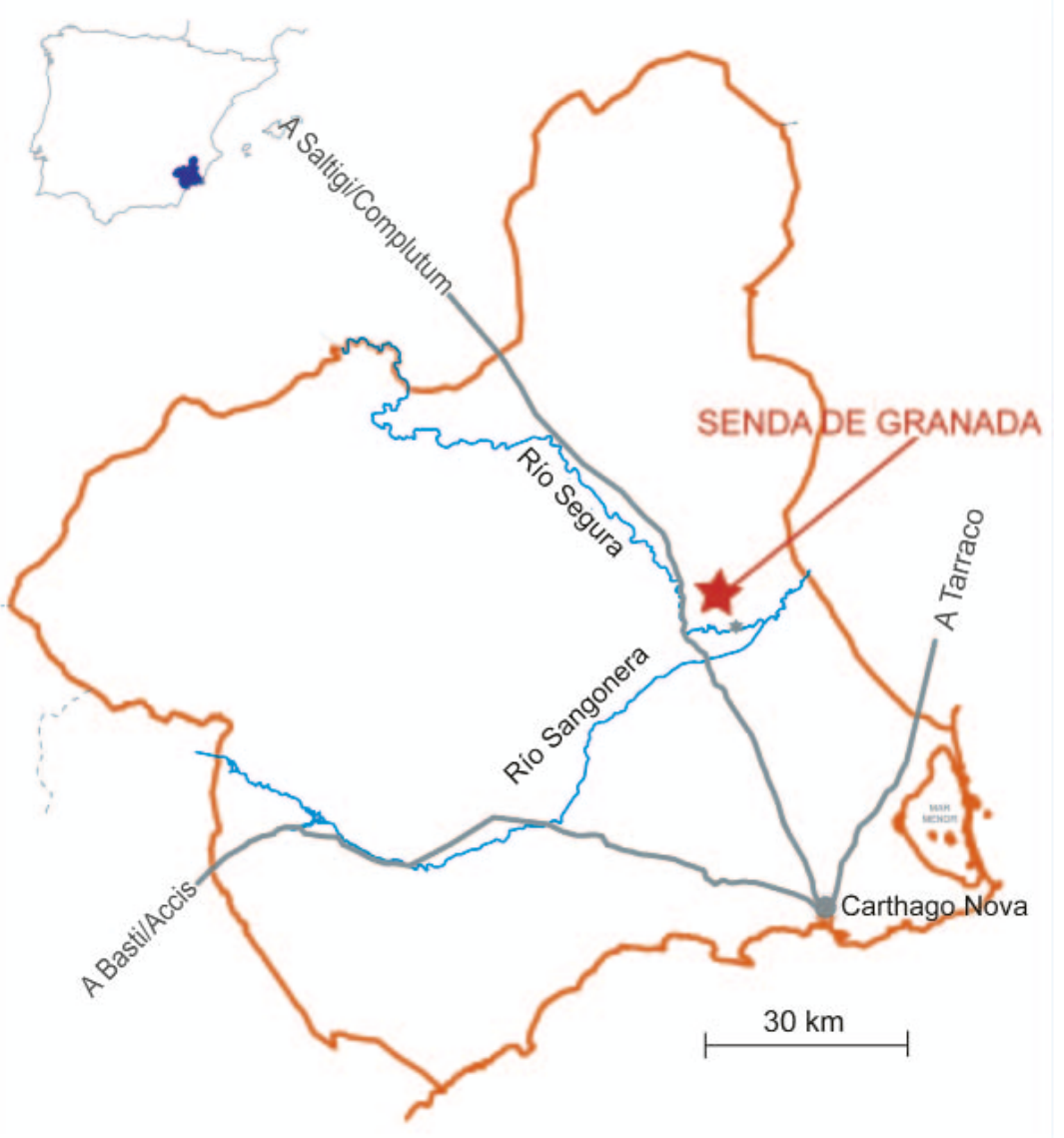

Figura 1: Localización de la Senda de Granada.

las laderas y fondos de valle se situaron hornos, silos, grandes vertederos y un hábitat de carácter muy modesto, en las partes llanas.

Los restos documentados forman parte del sector productivo (pars fructuaria) de una uilla plenamente operativa en el siglo IV, cuando almazaras, alfares y posibles fraguas elaboraban productos destinados al autoabastecimiento y a una probable comercialización de sus excedentes en contenedores posiblemente fabricados en sus propias instalaciones.

Hacia finales del siglo V y comienzos del siglo VI se detecta un proceso generalizado de amortización y cambio de uso. Ciertas instalaciones productivas sufrieron transformaciones incompatibles con su función inicial. Algunas estancias directamente se transforman en espacios de habitación identificados por la presencia de hogares-cocina, mientras que otras se obliteran y se levantan sobre ellas nuevas unidades domésticas. En otros casos se detectan construcciones nuevas adosadas a las anteriores o se aprecian nuevos signos de actividad que denotan importantes cambios de uso como la presencia de grandes vertederos en antiguas áreas trabajo como patios o los espacios abiertos asociados a posibles almacenes.

Hacia finales del siglo VI el establecimiento tardorromano comenzó a despoblarse, concluyendo la ocupación romana a principios del siglo VII, coincidiendo con la conquista y destrucción de la bizantina
Carthago Spartaria a manos de los godos (Suintila/ Sisebuto). No se vuelve a detectar presencia humana hasta la etapa árabe (siglos X-XIII).

A lo largo de su ocupación se fueron sucediendo en el emplazamiento varios cementerios de inhumación (occidental, septentrional y oriental) localizados en zonas perimetrales del área habitada. También se han documentado diversos espacios con enterramientos aislados, así como un reducido grupo de enterramientos privilegiados que se distribuyen en distintos ámbitos de un edificio de posible carácter cultual, de donde proceden los clavos de féretros objeto de este estudio (Fig. 2).

Este posible edificio cultual (Fig. 3) se encuentra situado al oeste del establecimiento. Se han localizado restos de varios paramentos (a nivel de cimentación) que definían, aunque de forma incompleta, una doble estancia rectangular con una perfecta orientación esteoeste. Al norte se desarrolla una sala estrecha, sin cierre occidental, de 3,58 $\mathrm{m}$ anchura por 14,68 $\mathrm{m}$ de longitud conservada. Al sur, otra sala de igual longitud quedaba delimitada al oeste con los residuos de un paramento (en L) ya inexistente, que nos facilita su anchura, 7,55 m. Al oeste de este muro aparecen alineadas de norte a sur un conjunto de 9 sepulturas, ordenadas en dos hileras paralelas, todas ellas orientadas Este-Oeste. Al sureste de este conjunto se conservan los restos constructivos de otro paramento con una fábrica similar (también dispuesto 


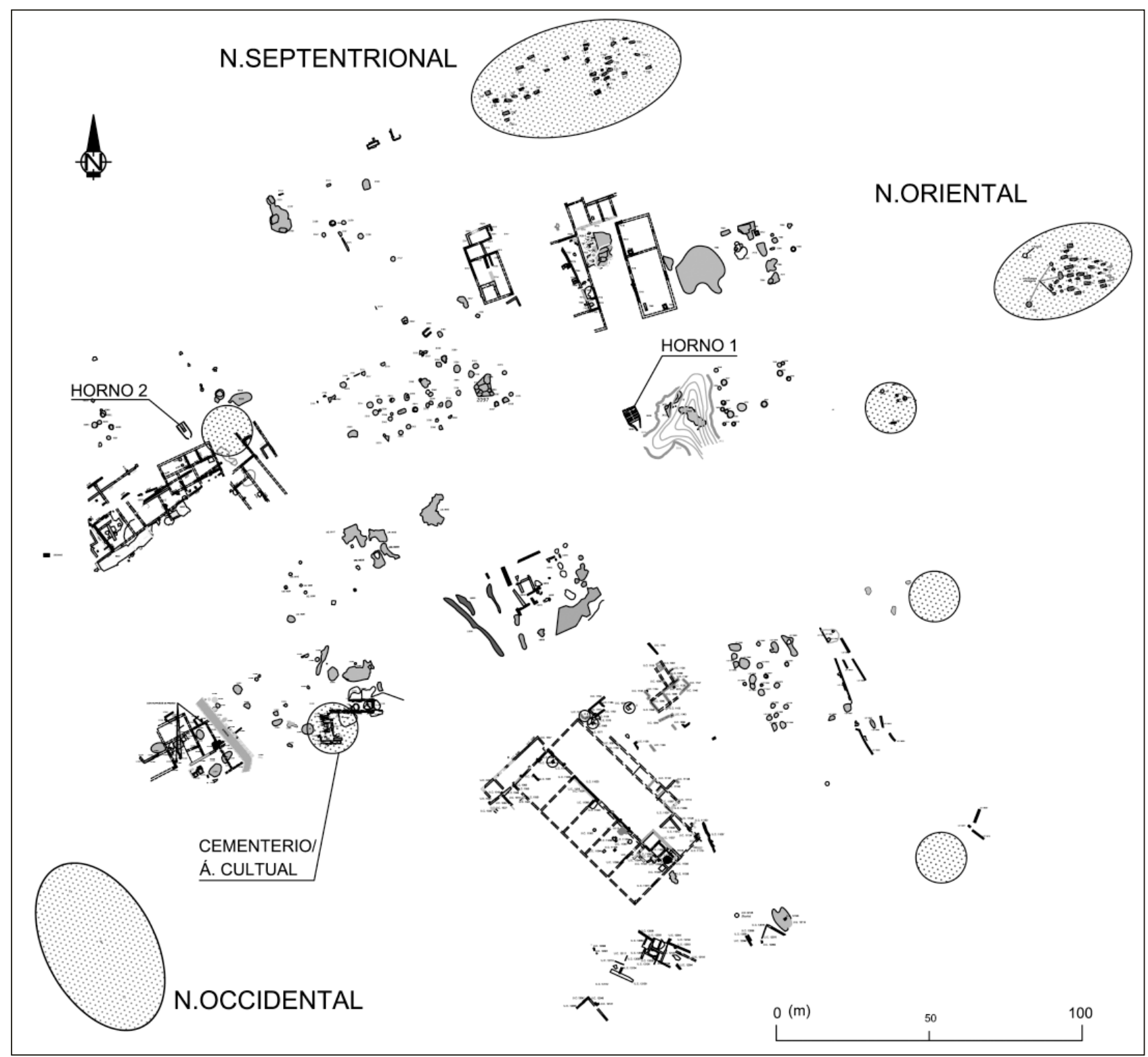

Figura 2: Planta general de los sectores excavados en la Senda de Granada.

en «L») que concretaba el ángulo sudoriental de la nave meridional del edificio y sus dimensiones $(17,48 \mathrm{~m}$ de largo por 3,24 $\mathrm{m}$ de ancho, medidas externas).

Dicho inmueble presenta, por lo tanto, una ancha nave central, definida por los cimientos de su paramento septentrional y, probablemente, del occidental y meridional. Este paramento, en sentido norte-sur determina un espacio singular al oeste de la nave central. Por el norte, flanquea otra nave, de menor anchura, delimitada por un paramento longitudinal paralelo y otro que marca el cierre oriental de dicho espacio. Precisamente con este límite oriental se alinea el tramo menor cuyo ángulo señala el cierre meridional de esta nave. En definitiva, a pesar de los escasos restos estructurales documentados, se puede restituir la planta de un edificio basilical, del que tan solo faltaría la cabecera (sin restos documentados) para alcanzar una reconstrucción completa.
El probable carácter sagrado del edificio determinó su uso como un área cementerial privilegiada. Los ámbitos empleados para ello fueron la sala situada al oeste de la nave central (posible nártex o vestíbulo) y las dos laterales, aunque de la nave septentrional apenas quedan restos de un único enterramiento (T9). En cada sector las sepulturas muestran una técnica constructiva diferente: la mampostería tomada con argamasa de cal (T1, T2, T3, T4 y T5), el posible vestíbulo, y las losas de piedra en la nave meridional (T6, T8, T10 y T11). La diferente localización espacial y las distintas técnicas constructivas, llevan a plantearnos la posible existencia de dos momentos constructivos o bien la coexistencia de dos grupos sociales relevantes.

Las cinco sepulturas emplazadas al oeste de la nave central (T1-T5) están construidas con fábrica de mampostería, observándose el empleo de argamasa de cal en los muretes perimetrales de las sepulturas T1, 


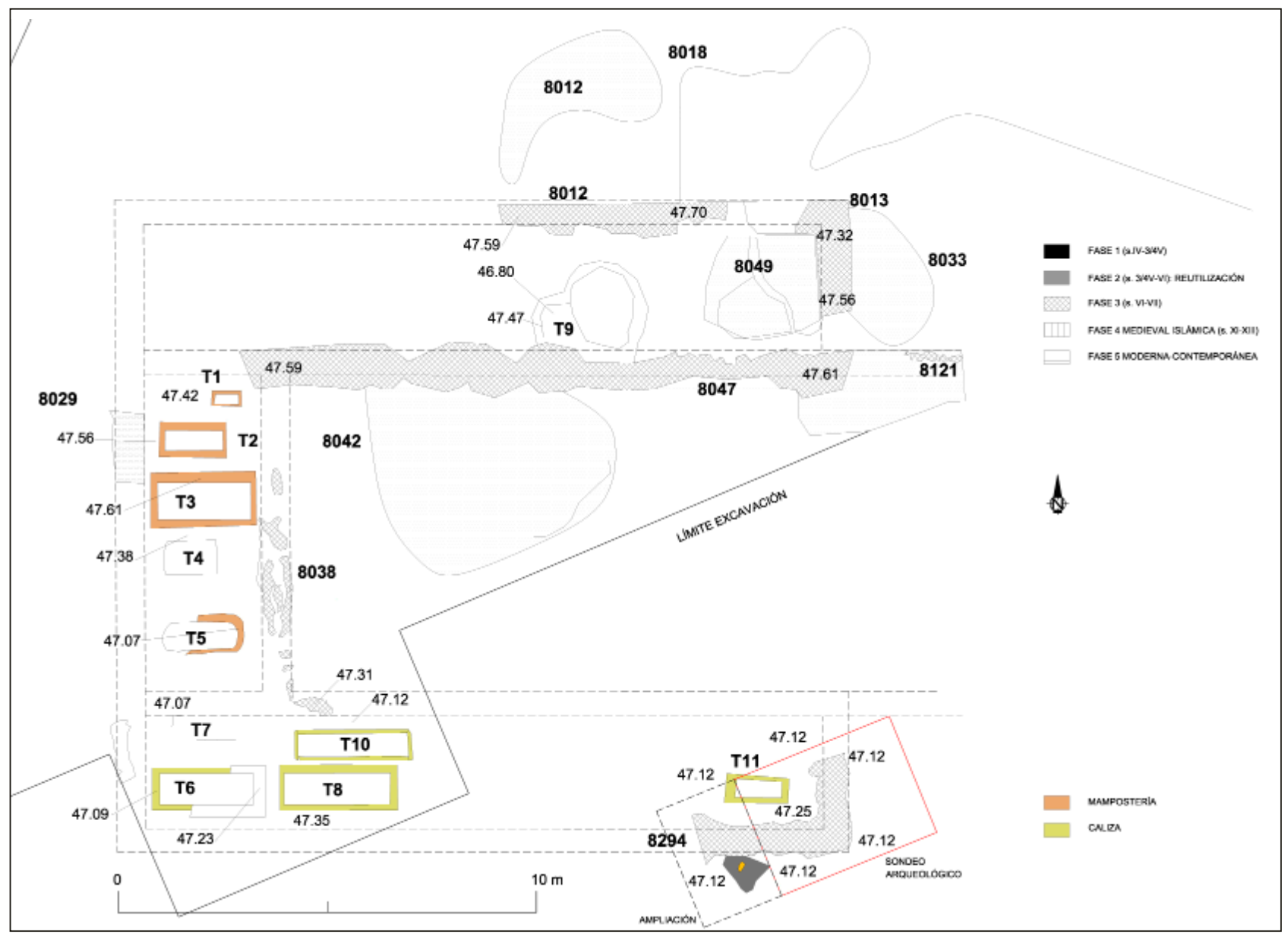

Figura 3: Planta y localización de las sepulturas en el edificio de culto de Senda de Granada.

T2 y T3, y en la base conservada de las restantes (T4 y T5). Las sepulturas T6, T8 y T10 (nave meridional) están confeccionadas con grandes losas de arenisca de espesor variable, unidas con mortero de cal y piedra menuda. El único sarcófago monolítico documentado en Senda de Granada corresponde al enterramiento infantil de la sepultura T11. Está labrado en calcarenita amarillenta y tiene forma trapezoidal con la cabecera más ancha que los pies.

Todas las sepulturas carecían de cubierta al haber sido expoliadas en época antigua. Los escasos restos óseos conservados permiten no obstante observar que los individuos estaban colocados en posición decúbito supino, con los miembros extendidos, dentro de una caja de madera a juzgar por los trozos de clavo de hierro (objeto de este estudio) localizados a lo largo de los costados. Solo en dos casos se han documentado objetos de indumentaria o adorno personal. En la tumba 3 se registró una pieza fragmentada con un cabujón ovalado y un alfiler de bronce de cabeza esférica; y en el interior de la tumba 10, una hebilla ovalada con hebijón recto de base ancha de tipo escutiforme y una fíbula discoidal con decoración geométrica de técnica mixta de cabujones y celdillas, cubiertas con láminas de color granate y el cabujón central con una piedra de color verde (García Blánquez y Vizcaíno Sánchez, en prensa).
Los demás elementos metálicos recuperados del interior de las sepulturas T2, T3, T5, T6, T8 y T10 forman un conjunto de 152 piezas de hierro, identificadas como herrajes de los féretros de madera, de los cuales 150 son clavos y los otros dos corresponden a una posible bisagra anular y a una pieza angular. Entre los primeros identificamos 42 cabezas (algunas conservan sólo una pequeña fracción) y 108 fragmentos de vástago (representados a veces por finas esquirlas).

Las peculiares características morfológicas de estos clavos y la conservación en algunos de ellos de restos mineralizados de madera, determinaron su estudio. Desde el punto de vista formal, estos clavos ofrecen diferencias a los comúnmente documentados en cementerios tardorromanos, de cabeza circular plana o semiesférica y vástago de sección cilíndrica o cuadrada. En nuestro caso la parte del remache ofrece tres variantes: la forma triangular (SG-E1-8051-3-3), la triangular con estrechamientos laterales marcando un extremo puntiagudo (SG-E1-8051-5-3) y el semicircular (SG-E1-8050-1) (Fig. 4). Respecto de la espiga, la sección puede ser también romboidal, además de cuadrada. En algunos casos las cabezas presentan un acabado diferente de aquellos trabajados sólo en la fragua, con restos aparentemente vitrificados de color gris metalizado y granate, semejante a la pasta vítrea. 
En cuanto a la cronología que podemos atribuir a este conjunto de herrajes, a la espera de la datación radiocarbónica de los restos óseos, son los objetos de adorno personal localizados en la T10 los únicos elementos de datación disponibles. Dichas piezas tienen un amplio recorrido cronológico, pues aparecen en la indumentaria de las últimas décadas del siglo $\mathrm{V}$ perdurando a lo largo de casi cien años (560/80) (Ripoll López, 1998), sin descartar incluso que alcancen las primeras décadas del s.VII.

\section{MATERIAL Y MÉTODOS}

Los fragmentos de vástago de clavo que presentaban restos de madera adheridos fueron manualmente recuperados durante el proceso de excavación. En concreto, los restos de madera estudiados (18 esquirlas) proceden de un total de 10 fragmentos de vástago de clavo (Fig. 5) de las sepulturas T3, T5, T6, T8 y T10 (Fig. 3).

La madera mineralizada formaba una fina capa, muy degradada, que cubría algunos espacios del vástago. Para realizar su estudio resultaba imprescindible separar del clavo pequeñas esquirlas (de al menos 4 $\mathrm{mm}$ ), ya que el proceso de identificación taxonómica implica la fragmentación manual de la madera para observar sus diferentes planos anatómicos. Esta labor resultó bastante dificultosa y no en todos los casos fue posible una observación completa de la muestras.

La identificación taxonómica fue llevada a cabo mediante la observación de las esquirlas en un microscopio metalográfico Nikon, con óptica de campo claro/ oscuro y de 50 a 500 aumentos (magnificación x 5 , x 10, x20 y x50). Cuando fue posible, los planos anatómicos estudiados para cada fragmento fueron el transversal, perpendicular al eje del tronco, el longitudinal tangencial, tangente al círculo que forman los anillos de crecimiento y el longitudinal radial, corte paralelo al eje longitudinal del tronco. La identificación taxonómica

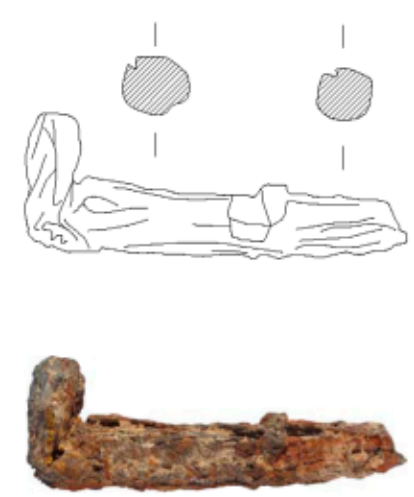

SG-E1-8051-3-3
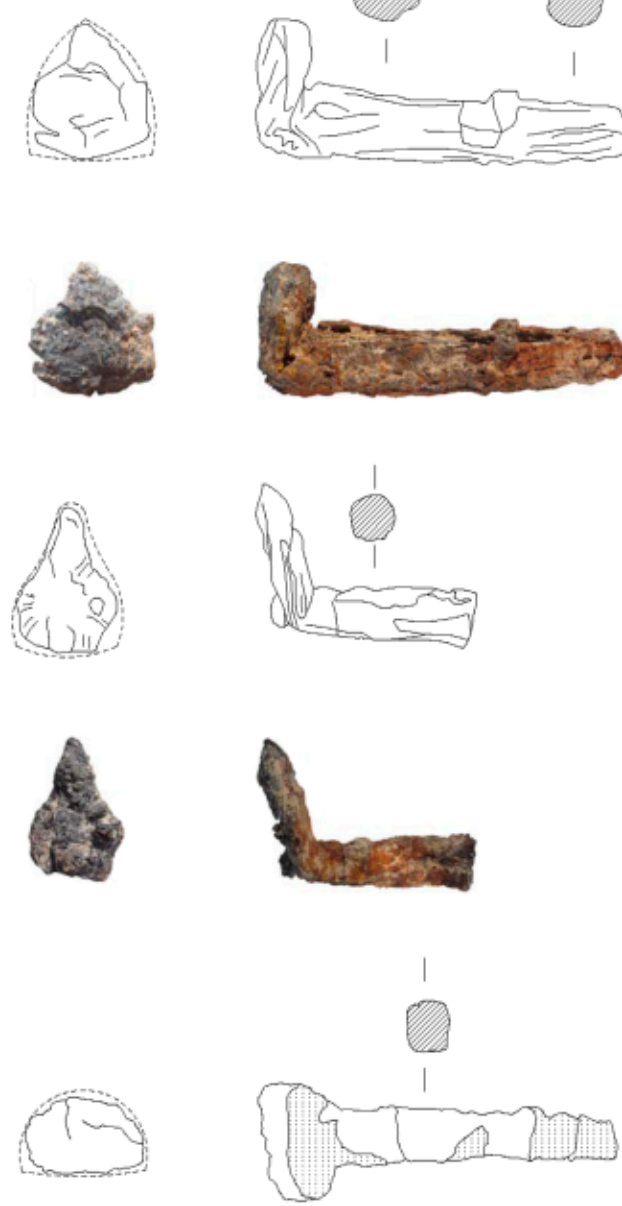

SG-E1-8050-1
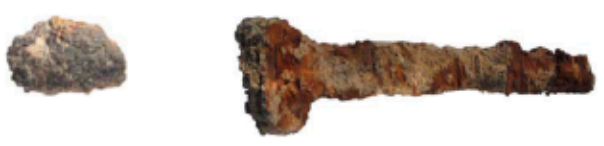
$3 \mathrm{~cm}$

Figura 4: Morfología de los clavos hallados en Senda de Granada.

\begin{tabular}{|c|c|c|l|}
\hline \multirow{3}{*}{ Sepultura } & $\begin{array}{c}\text { Clavos estudiados } \\
\text { (Sigla) }\end{array}$ & $\begin{array}{c}\text { No de frag. de madera } \\
\text { estudiados }\end{array}$ & \multicolumn{1}{|c|}{ Identificación taxonómica } \\
\hline \multirow{3}{*}{ T3 } & SG-E1-8051 & 2 & Coniferae \\
\cline { 2 - 4 } & SG-E1-8051 & 2 & Coniferae \\
\hline \multirow{3}{*}{ T5 } & SG-E1-8085 & 2 & Coniferae \\
\cline { 2 - 4 } & SG-E1-8085 & 2 & Pinus tipo mediterráneo \\
\cline { 2 - 4 } & SG-E1-8085 & 2 & Coniferae \\
\hline \multirow{2}{*}{ T6 } & SG-E1-8085 & 1 & Coniferae \\
\hline T8 & SG-E1-8181 & 2 & Coniferae \\
\hline \multirow{2}{*}{ T10 } & SG-E1-8188 & 1 & Coniferae \\
\cline { 2 - 4 } & SG-E1-8268 & 3 & Pinus tipo mediterráneo \\
\hline
\end{tabular}

Figura 5: Material analizado e identificación taxonómica de los restos. 
definitiva se apoyó en la consulta de diversos atlas de anatomía de la madera (Schweingruber, 1978; 1990; Vernet et alii, 2001; García Esteban et alii, 2003) y en la comparación del material arqueológico con una colección de referencia de madera actual carbonizada.

Las imágenes presentadas aquí fueron adquiridas gracias al programa de análisis de imágenes NIS Elements D 3.1 para Nikon.

\section{RESULTADOS E INTERPRETACIÓN}

La conservación a veces muy deficiente de los tejidos leñosos presentes en los diferentes fragmentos de vástago ha tenido como consecuencia un grado de discriminación taxonómica desigual.

La madera adherida a los cuatro fragmentos de clavo estudiados para las sepulturas T3, T6 y T8 (Fig. 6) es la que ofrece resultados menos concluyentes. Han permitido únicamente la observación parcial de dos planos anatómicos de su madera adherida, el transversal y el longitudinal tangencial (salvo en el caso de la T6 en donde sólo se observan tejidos leñosos indeterminables). En el plano transversal (T3, imágenes $\mathrm{a}, \mathrm{b}, \mathrm{c} ; \mathrm{T} 8$, imágenes a, b) se observa la presencia de leño homóxilo, compuesto por traqueidas, elemento que integra el tejido xilemático de las coníferas. No ha sido posible, sin embargo, distinguir si existen o no canales resiníferos, propios fundamentalmente de las diferentes especies de pino. En el plano longitudinal tangencial (T3, imagen d) se han detectado algunas células uniseriadas correspondientes a los radios de una conífera, si bien no ha podido determinarse si se trata de radios homogéneos o heterogéneos, característicos de cupresáceas y pináceas respectivamente. La identificación taxonómica, por lo tanto, nos permite únicamente conocer que la madera adherida a estos clavos pertenece al Orden Coniferae (Fig. 5), pudiendo corresponder a diferentes familias, como Pinaceae (pinos, abetos, cedros...) o Cupressaceae (enebros, sabinas, cipreses...).

Las sepulturas T5 y T10 (Fig. 7) han permitido una identificación taxonómica más precisa que las anteriores. En ambos casos ha sido posible la observación de sus tres planos anatómicos. El transversal (T5, imágenes a, b, c; T10, imágenes a, e) presenta traqueidas que sitúan a esta madera dentro del Orden Coniferae. Como en los casos anteriores, la presencia de canales resiníferos no ha podido ser constatada. Los radios uniseriados (T5, imágenes d, e, g; T10, imagen b) o las punteaduras areoladas (T10, imagen c) presentes en el plano longitudinal tangencial confirman esta adscripción al grupo de las coníferas. Sin embargo, ha sido la observación del plano longitudinal radial (T5, imagen f; T10, imagen 10) la que ha permitido alcanzar una identificación de rango genérico. Aquí se ha observado la presencia de punteaduras pinoides en los campos de cruce, cuya disposición, agrupadas de dos en dos (a veces cuatro) (Fig. 8), permite identificar que se trata del género Pinus y del tipo mediterráneo (Fig. 5), excluyendo a los de alta montaña (Pinus nigra, Pinus sylvestris), que presentan punteaduras fenestriformes. Las especies de pino de carácter mediterráneo que se dan en la Península Ibérica y que pueden obedecer a

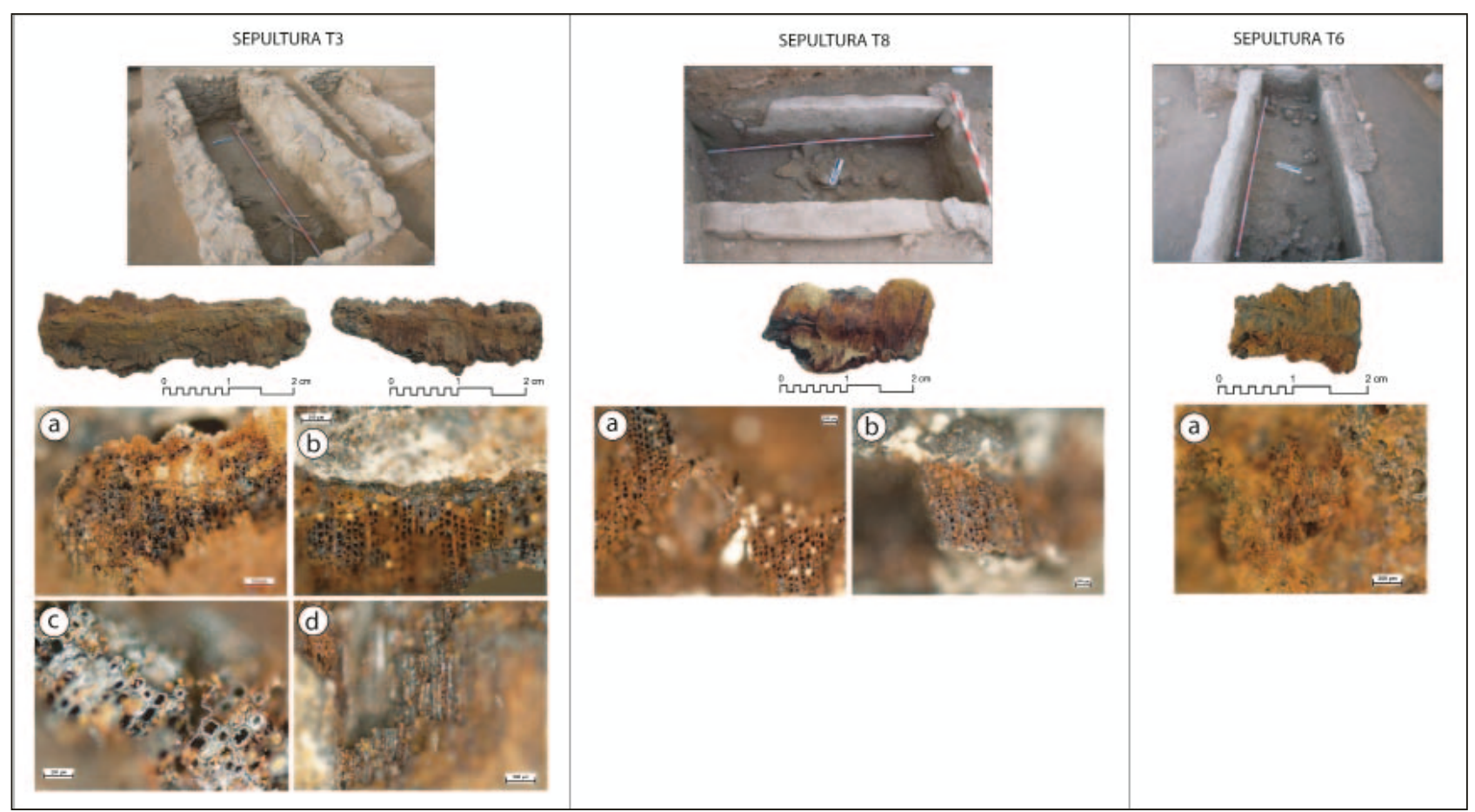

Figura 6: Sepulturas T3, T8 y T6, fragmentos de vástago estudiados e imágenes de la estructura leñosa observada en microscopio óptico. Magnificación, T3, a: x5, b: x5, c: x10, d: x5; T8, a: x5, b: x5; T6, a: x5. 


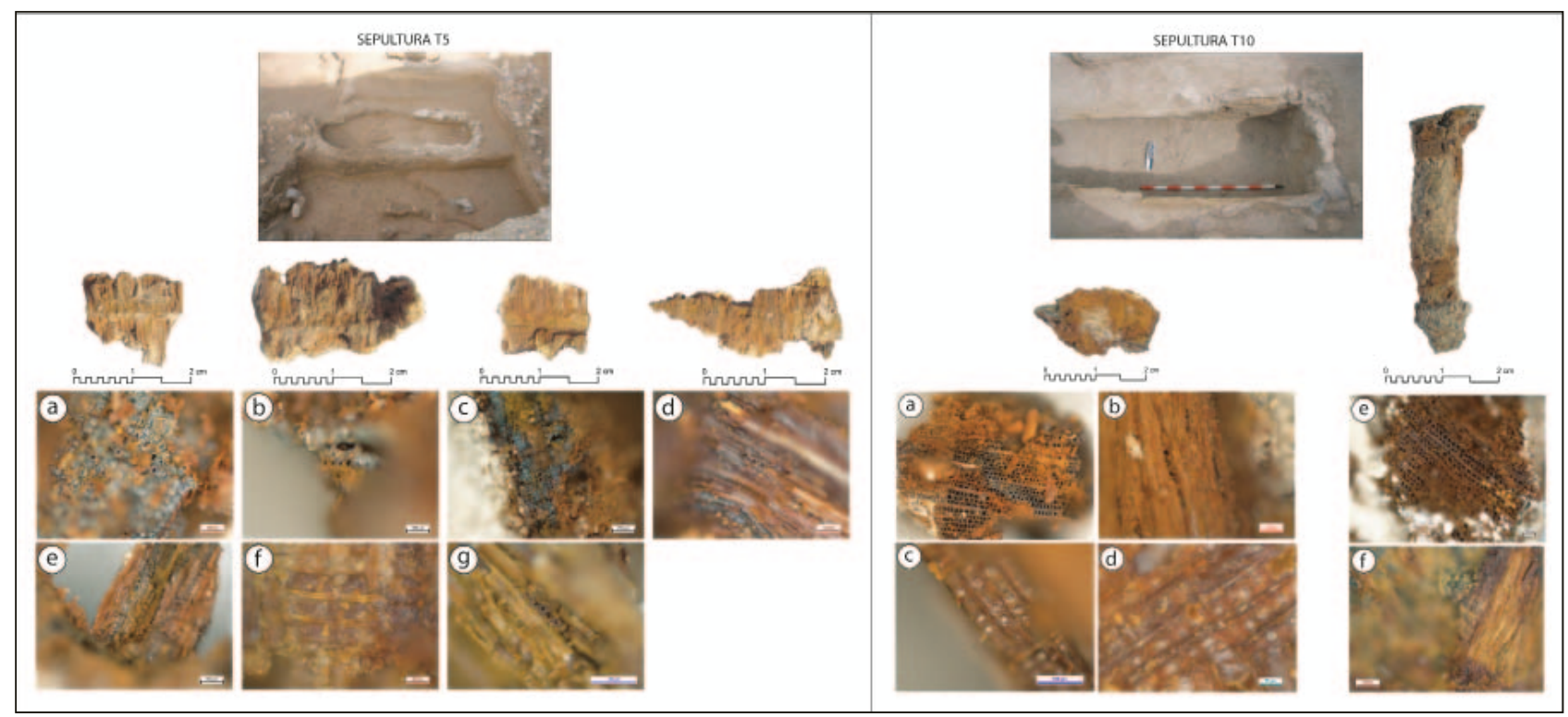

Figura 7: Sepulturas T5 y T10, fragmentos de vástagos estudiados e imágenes de la estructura leñosa observada en microscopio óptico. Magnificación, T5, a: x10, b: x5, c: x5, d: x10, e: x5, f: x50, g: x20; T10, a: x5, b: x10, c: x20, d: x50, e: x5, f: x10.

la anatomía observada son Pinus halepensis (pino carrasco), Pinus pinea (pino piñonero) y Pinus pinaster (pino rodeno). De acuerdo a sus afinidades ecológicas termófilas, fue más probable el uso en esta zona de los dos primeros, frente a Pinus pinaster, mejor adaptado a condiciones de tipo submediterráneo y a terrenos de carácter dolomítico.

Sabemos, por lo tanto, que todos los ataúdes o parihuelas empleados en la necrópolis de la zona de culto de Senda de Granada estuvieron elaborados con madera de conífera, sin ningún indicio de utilización de frondosas. Pese a que en otros estudios se ha detectado el uso de diferentes maderas para la elaboración de un mismo féretro (Hunot, 1996), en el caso de Senda de Granada tampoco es posible plantear esta posibilidad. El espectro de especies pertenecientes al orden Coniferae que pudo utilizarse en época tardoantigua es muy amplio, ya que incluiría las autóctonas de esta región (entre las más comunes Pinus halepensis, Juniperus oxycedrus o Juniperus phoenicea), de crecimiento espontáneo en las proximidades del sitio, pero también un nutrido grupo de taxones que pudieron ser cultivados o simplemente importados desde lugares lejanos, hecho que se observa desde época romana (García

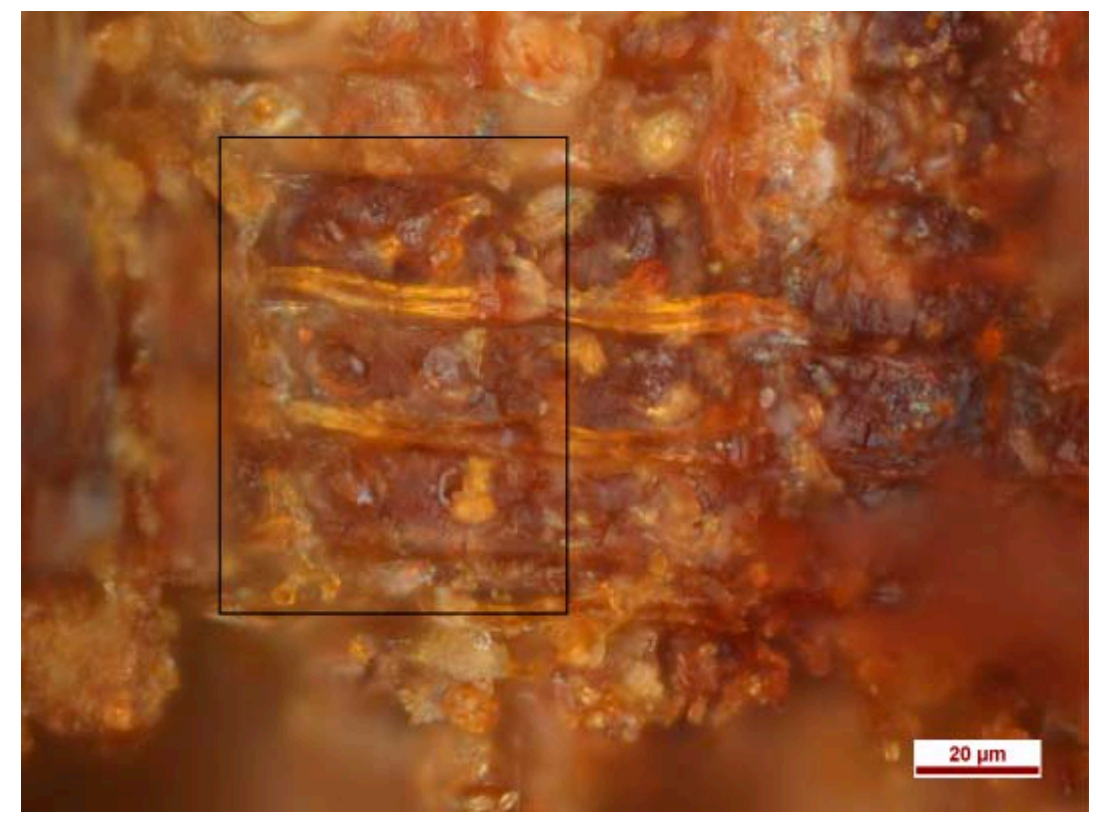

Figura 8: Detalle de las punteaduras de los campos de cruce de observadas en la madera adherida a uno de los vástagos de la sepultura $\mathrm{T} 5$. 
Martínez y Matilla Séiquer, 2008; García Martínez, 2009). No procede, por lo tanto, centrar la discusión de este trabajo en valorar una infinidad de posibilidades inciertas. Al contrario, resulta conveniente abordar las diferentes cuestiones que se plantean en relación con el muy probable uso de madera de pino carrasco o de pino piñonero para la elaboración de los ataúdes estudiados en las sepulturas T5 y T10.

Pinus halepensis es una especie circunmeditarránea muy frecuente en toda la Península Ibérica y predominante en el Sureste, desde el nivel del mar hasta los $1500 \mathrm{~m}$ en solanas. Tiene amplia tolerancia ecológica, con una gran resistencia a la sequía y poca a las heladas. Es indiferente edáfico aunque se desarrolla mejor en suelos básicos. Por su parte, Pinus pinea presenta su óptimo desarrollo desde el nivel del mar hasta los 800-1000 m de altitud. Crece preferentemente en suelos arenosos y sueltos, como arenales marítimos, dunas fijas o los bancos arenosos aluviales de algunos ríos (Costa et alii, 2001). Prefiere los sustratos de composición silícea (López González, 2001), si bien puede aparecer asociado a sedimentos carbonatados en calizas. Resiste bien las altas temperaturas y su rango de precipitaciones óptimo se encuentra entre los 400-1000 mm, aunque soporta la sequía estival (Galán et alii, 1998).

Las afinidades ecológicas de ambas especies, por lo tanto, harían posible su desarrollo natural en esta zona. En lo que concierne al pino carrasco, se trata de hecho de una de las especies arbóreas dominantes de las formaciones forestales mediterráneas peninsulares durante el Holoceno reciente. El aumento de sus porcentajes en el piso termomediterráneo comienza en el Neolítico (c. 5900 BP) (Badal et alii, 1994), en relación con la acción antrópica sobre determinadas áreas $\mathrm{y}$ en detrimento de las formaciones de quercíneas y mesófitos dominantes en el óptimo climático atlántico. La predominancia de este pino se constata sobre todo a partir de la Edad del Bronce (c. 3800 BP), cuando se produce una apertura del paisaje debido a factores como el proceso de aridificación climática (Jalut et alii, 2000; 2009, Pantaleón-Cano et alii, 2003) y el desarrollo de patrones económicos basados en la depredación de los recursos naturales (Castro et alii, 1999; Carrión et alii, 2003; 2007). En cronologías romanas, tardorromanas y medievales, Pinus halepensis sigue dominando los espacios forestados a escala regional (Grau, 1990; García Martínez y Matilla Séiquer, 2008; Grau y De Haro, 2004; García Martínez y Ramírez Águila 2009; 2010). En el caso de Pinus pinea, su autoctonía en la península es clara, apareciendo ya su madera en el sur desde el Paleolítico superior y Neolítico en la Cueva de Nerja (Badal, 1996; Aura et alii, 2002). En el Sureste está documentado como combustible en los yacimientos argáricos de Fuente Álamo (Carrión Marco, 2004; 2005), donde también aparecieron piñones (Stika, 1988) y en Punta de los Gavilanes, hasta el siglo III a.C. (García Martínez et alii, 2008). También se constata su presencia en el contexto regional en el caso de los yacimientos protohistóricos de Alt de Benimaquia (Grau y Duque, 2007) y La Fonteta (Grau, 2007), en Guardamar de Segura, donde la plantación de pinos piñoneros ha contribuido a la contención de las dunas marinas actuales. Para época romana esta especie aparece en los niveles de incendio de la villa romana de Gabia (Granada), utilizada posiblemente como material constructivo. En este caso se ha planteado tanto la posibilidad de que formara parte de la vegetación forestal espontánea, como de que se tratara de una especie cultivada en la villa (Rodríguez-Ariza y Montes Moya, 2010). Esta es una hipótesis que también contemplamos para Senda de Granada, ya que su cultivo es una práctica constatada en todo el ámbito mediterráneo y en la Península Ibérica en época romana (Buxó, 1997). En este momento se produce un fuerte incremento de restos que sugieren el consumo habitual de piñones (André, 1981; Matterne, 2001), a veces transportados desde lugares lejanos (Girard y Tchernia, 1978).

La adquisición de madera de estas especies para la elaboración de los ataúdes estudiados pudo entonces producirse en una zona más o menos próxima al asentamiento. Pinus halepensis sería predominante tanto en las zonas llanas como en las elevaciones próximas. En el caso del pino piñonero, las maderas pudieron provenir del ámbito local (todavía hoy se encuentran ejemplares próximos al yacimiento) o regional, como por ejemplo los arenales costeros. Menos probable es que se tratara de árboles plantados para la producción de piñones, ya que en general aquéllos con valor económico se talarían menos frecuentemente (así lo demuestran la mayoría de estudios antracológicos). En todo caso, se trata de maderas para cuya obtención no fue necesario realizar grandes desplazamientos y que no implicarían tampoco el establecimiento de contactos comerciales a media o larga distancia.

Además de su proximidad al asentamiento, el uso de ambos pinos se debió probablemente a una selección consciente relacionada con sus propiedades físico-mecánicas. El criterio prioritario de selección fue con seguridad la talla de su tronco, teniendo en cuenta que en la zona la vegetación forestal habría sufrido un fuerte retroceso frente a un incremento de la vegetación arbustiva y esteparia (Pantaleón-Cano et alii, 2003; Fuentes et alii, 2005). En este contexto de carencia de elementos arbóreos, el tronco de los pinos estaría entre los pocos que permitiría la elaboración de tablones de un tamaño y anchura suficientes para la construcción de los ataúdes. La madera de Pinus halepensises de calidad media, dura, de grano fino y ha sido utilizada tradicionalmente para la realización de instrumentos de carpintería y construcción de mediano tamaño. La madera de pino piñonero, a pesar de que es muy difícil de trabajar y bastante resinosa, es también muy resistente a la humedad, lo cual ha favorecido tradicionalmente su utilización en carpintería en general, para la elaboración de vigas para la construcción, traviesas de ferrocarril y para 
la construcción de barcos y utensilios para la pesca (López González, 2001).

Los restos arqueológicos confirman que tanto $\mathrm{Pi}$ nus halepensis como Pinus pinea fueron seleccionados como material constructivo en el cuadrante sureste peninsular. El pino carrasco se presenta de hecho como el elemento central en el modelo constructivo observado en el Sureste en el Bronce pleno (Rodríguez Ariza, 1992, 2008; Machado Yanes et alii, 2004; 2009; García Martínez et alii, 2011). Aparece igualmente en contextos de destrucción por incendio de yacimientos ibéricos y romanos (Rodríguez Ariza, 1992; Rodríguez Ariza et alii, 1999; Grau, 1990; García Martínez, 2009). Por su parte, el pino piñonero aparece como material constructivo preferencial en los casos por ejemplo del edificio de la Edad del Bronce relacionado con la actividad pesquera en la Punta de los Gavilanes (Ros Sala et alii, 2008; García Martínez, 2009) o de las instalaciones de la ya mencionada villa romana de Gabia (Rodríguez-Ariza y Montes Moya, 2010).

Las sepulturas estudiadas, localizadas en un posible edificio cultual, pertenecerían a un grupo de población socialmente preeminente. La cuidada arquitectura funeraria y la presencia de adornos personales de prestigio, parecen confirmar esta interpretación. Sin embargo, en los féretros se emplea madera común en la zona, cuando cabría esperar el uso de maderas menos corrientes. En todo caso, al no disponer de análisis similares para las demás áreas cementeriales de Senda de Granada ni de estudios comparables en el resto del ámbito peninsular, no es posible verificar si la madera para uso funerario en otros grupos sociales tardorromanos era, además, considerada un material de prestigio. Las perspectivas de futuro de esta línea de investigación, por lo tanto, pasan por tomar en consideración estos objetos como elementos que ofrecen una información valiosa para la caracterización de las costumbres sociales, culturales y rituales de la sociedad de cualquier época.

\section{CONCLUSIONES}

En este trabajo se ha abordado el estudio anatómico e identificación taxonómica de los restos de madera mineralizada adherida a clavos de hierro integrantes de los féretros de 5 sepulturas de la necrópolis tardorromana de Senda de Granada (Murcia).

Los resultados indican que los ataúdes fueron elaborados exclusivamente en madera de conífera. En dos de las tumbas los féretros se fabricaron con madera de pino de tipo mediterráneo, muy probablemente Pinus halepensis (pino carrasco) o Pinus pinea (pino piñonero), de acuerdo con las preferencias ecológicas de estas especies.

Los datos arqueobotánicos muestran que ambas especies formaron parte de la vegetación local, ya fuera de forma espontánea o, en el caso del pino piñonero, también cultivado para el consumo de piñones. $\mathrm{Su}$ adquisición no implicaría, por lo tanto, procesos de importación a media o larga distancia. Esto denota que la madera de los sarcófagos no constituiría un elemento de prestigio del grupo de clase social privilegiada inhumado en esta necrópolis.

\author{
María Soledad García Martínez \\ Facultad de Letras \\ Universidad de Murcia \\ C/ Santo Cristo, 1 \\ 30001 Murcia \\ msgarmar@um.es \\ Luis Alberto García Blánquez \\ ArqueoTec C.B. \\ C/ San Patricio, $10-2^{\circ}-4$ \\ 30004 Murcia \\ luisgblan@gmail.com
}

Dpto. de Prehistoria, Arqueología, Historia Antigua,

Historia Medieval y Ciencias y Técnicas Historiográficas

\section{BIBLIOGRAFÍA}

ANDRÉ, J., 1981: L'alimentation et la cuisine à Rome, Paris.

AURA TORTOSA, J. E., JORDÁ PARDO, J. F., PÉREZ RIPOLL, M., RODRIGO GARCÍA, M. J., BADAL, E. y GUILLEM CALATAYUD, P., 2002: «The far south: The Pleistocene-Holocene transition in Nerja Cave (Andalucía, Spain)», Quaternary International, 93-94, 19-30.

BADAL, E., 1996: «La végétation du Paléolithique supérieur et de l'epipaléolithicque aux alentours de la Cueva de Nerja (Malaga, Nerja)», Supplément à la Revue d'Archéométrie, 171-176.

BADAL, E., BERNABEU, J. y VERNET, J.-L., 1994: «Vegetation changes and human action from the Neolithic to the Bronze Age (7000-4000 B.P.) in Alicante, Spain, based on charcoal analysis», Vegetation History and Archaeobotany, 3, 155-166.

BADAL, E., CABRERA, A., CORTÉS, M., SIMÓN, M.D., PARDO, A.I., SÁNCHEZ, A. y GÓMEZ, M.J., 2007: «Evidencias de materias orgánicas en instrumentos metálicos del Calcolítico y Edad del Bronce andaluces», en J. MOLERA, J. FARJAS, P. ROURA y T. PRADELL (Eds.), Avances en Arqueometría 2005. Actas del VI Congreso Ibérico de Arqueometría, Universitat de Girona, 229-239, Girona.

BARTHOLIN, T.S., 1978: «Dendrochronology, wood anatomy and Landscape development in south Sweden», en: Dendrochronology in Europe, BAR International Series, 51, 125-130, London.

BIRD, M.I., ASCOUGH, PH. L., YOUNG, I.M., WOOD, CH.V.ySCOTT, A.C., 2008: «X-ray microtomographic imaging of charcoal», Journal of Archaeological Science, 35, 2698-2706.

BOUCHAUD, CH., SACHET, I. y DELHOPITAL, N. 2009: «Les bois et les fruits des tombeaux nabatéens de Madâ'inSâlih/Hégra (Arabie Saoudite): les provenances des végétaux et leur utilisation en contexte 
funéraire», en C. DELHON, I. THÉRY-PARISOT y S. THIÉBAULT, Actes du colloque «Des hommes et des plantes. Exploitation et gestion des ressources végétales de la Préhistoire à nos jours». Session Usages et symboliques des plantes, XXXe Rencontres internationales d'archéologie et d'histoire d'Antibes. 22-24 octobre 2009, Antibes, Anthropobotanica, http://www.mnhn.fr/ museum/foffice/science/science/DocScientifique/publications/presentation/listeParution/ficheParution/fiche Contenu.xsp?CONTENU_ID $=4067 \&$ PARUTION ID $=2366 \&$ PUBLICATION_ID $=313 \& i d x=11 \&$ nav $=$ list eParution.

BUXÓ, R., 1997: Arqueología de las plantas. La explotación económica de las semillas y los frutos en el marco mediterráneo de la Península Ibérica, Barcelona.

CARRIÓN, J.S., FUENTES, N., GONZÁLEZ-SAMPÉRIZ, P., SÁNCHEZ QUITANTE, L., FINLAYSON, J.C., FERNÁNDEZ, S. y ANDRADE, A., 2007: «Holocene environmental change in a montane region of southern Europe with a long history of human settlement», Quaternary Science Reviews, 26, 1455-1475.

CARRIÓN, J.S., SÁNCHEZ GÓMEZ, P., MOTA, J.F., YLL, E.I. y CHAÍN, C., 2003: «Holocene vegetation dynamics, fire and grazing in the Sierra de Gádor, southern Spain», The Holocene, 13(6), 839-849.

CARRIÓN MARCO, Y., 2004: «Análisis antracológico del yacimiento de Fuente Álamo (Cuevas de Almanzora, Almería). Usos de la madera y paleovegetación», en L. HERNÁNDEZ ALCARAZ y M. S. HERNÁNDEZ PÉREZ (Eds.), La Edad del Bronce en tierras valencianas $y$ zonas limitrofes, 477-486, Alicante.

CARRIÓN MARCO, Y., 2005: La vegetación mediterránea y atlántica de la Península Ibérica. Nuevas secuencias antracológicas, Valencia.

CASTRO, P.V., CHAPMAN, R.W., SURIÑACH, S., LULL, V., MICÓ, R., RIHUETE, C., RISCH, R. y SANAHUJA, M.E., 1999: Proyecto Gatas 2. La dinámica arqueoecológica de la ocupación prehistórica, Sevilla.

COSTA, M., MORLA, C. y SAINZ, H. (Eds.), 2001: Los bosques ibéricos. Una interpretación geobotánica, Barcelona.

FUENTES, N., GARCÍA MARTÍNEZ, M. S., GONZÁLEZ SAMPÉRIZ, P., FERNÁNDEZ, S., CARRIÓN, J. S., LÓPEZ-CAMPUZANO, M. y MEDINA, J., 2005: «Degradación ecológica y cambio cultural durante los últimos cuatro mil años en el sureste ibérico semiárido», Anales de Biología, 27, 69-84.

GALÁN, P., GAMARRA GAMARRA, R. y GARCÍA VIÑAS, J. I., 1998: Árboles y arbustos de la Península Ibérica y Baleares, Madrid.

GARCÍA BLÁNQUEZ, L.A., 2010: «Senda de Granada: un asentamiento rural tardoantiguo en el entorno de Murcia», en J.M. NOGUERA CELDRÁN (Ed.), Poblamiento rural romano en el sureste de Hispania.15 años después, 467-513, Murcia.

GARCÍA BLÁNQUEZ, L.A. y VIZCAÍNO SÁNCHEZ, J., (e.p.): «Elementos metálicos de época tardoantigua procedentes de la Senda de Granada (Murcia)».
GARCÍA ESTEBAN, L., GUINDEO CASASUS, A., PERAZA ORAMAS, C. y DE PALACIOS, P., 2003: La madera y su anatomía, Madrid.

GARCÍA MARTÍNEZ, M.S., 2009: Recursos forestales en un medio semiárido. Nuevos datos antracológicos para la Región de Murcia desde la Edad del Bronce hasta época medieval. Tesis doctoral, Universidad de Murcia.

GARCÍA MARTÍNEZ, M. S. y MATILLA SÉIQUER, G., 2008: «Rasgos medioambientales y aprovechamiento de los recursos leñosos en la Vega del Segura durante el siglo I d.C.», en S. ROVIRA LLORENS, M. GARCÍA-HERAS, M. GENER MORET y I. MONTERO RUIZ (Eds.), Actas VII Congreso Ibérico de Arqueometría, Madrid, 8-10 octubre de 2007, 169-179, Madrid.

GARCÍA MARTÍNEZ, M.S. y RAMÍREZ ÁGUILA, J.A., 2009: «La vegetación en el entorno de Jumilla durante los siglos XII-XIII a partir del antracoanálisis de la intervención preventiva en la C/ Santa María n ${ }^{\circ} 19$ », Anales de Prehistoria y Arqueología, 25-26, 257-274.

GARCÍA MARTÍNEZ, M.S. y RAMÍREZ ÁGUILA, J.A., 2010: «La madera como combustible artesanal en el Sureste de la Península Ibérica (Jumilla, Murcia) durante los siglos XII-XIII», Arqueología y Territorio medieval, $17,47-70$

GARCÍA MARTÍNEZ, M. S., GRAU, E. y ROS SALA, M. M., 2008: «El paisaje vegetal pre y protohistórico de la costa de Mazarrón (Murcia), según el antracoanálisis de Punta de los Gavilanes», Cuaternario y Geomorfología, 23 (3-4), 107-120.

GARCÍA MARTÍNEZ, M.S., MEDINA RUIZ, A.J. y GALLEGO CAMBRONERO, D., 2011: «Leña y madera de construcción en el poblado argárico de Barranco de la Viuda (Lorca, Murcia)», Zephyrus, LXVII, 129-143.

GIRARD, M. y TCHERNIA, A., 1978: «Remarques à propos des cônes de pin pignon (Pinuspinea) découverts sur l'épave de la Madrague de Giens», en A. A. TCHERNIA, P. POMEY y A. HESNARD, L'épave romaine de la Madrague de Giens (Var) (Campagnes 1972-1975), 117-118, Paris.

GRAU, E., 1990: El uso de la madera en yacimientos valencianos de la Edad del Bronce a la Época Visigoda. Datos etnobotánicos y reconstrucción ecológica según la Antracología. Tesis doctoral, Universidad de Valencia.

GRAU, E., 2007: «El paisaje vegetal», en P. ROUILLARD, E. GAILLEDRAT y F. SALA (Dirs.), L'établissement protohistorique de La Fonteta (fin VIIIe - fin VIe siècle av. J.-C), 416-422, Madrid.

GRAU, E. y DE HARO, S., 2004:«El paisaje vegetal de la Rápita de Guardamar en el siglo X», en R. AZUAR RUIZ (Coord.), El ribat califal. Excavaciones e investigaciones (1984-1992), Collection de la Casa de Velázquez 85, 153-158, Madrid.

GRAU, E. y DUQUE, D., 2007: «Los paisajes rurales protohistóricos: una síntesis arqueobotánica», en A. RODRÍGUEZ DÍAZ (dir.), Arqueología de la tierra. Paisajes rurales de la protohistoria peninsular, 297-325, Cáceres.

HANECA, K., DEFORCE, K., BOONE, M.N., VAN LOO, D., DIERICK, M., VAN ACKER, J. y VAN 
DEN BULCKE, J., 2011: «X-ray sub-micron tomography as a tool for the study of archaeological wood preserved through the corrosion of metal objects», $A r$ chaeometry, doi: 10.1111/j.1475-4754.2011.00640.x

HERNÁNDEZ GARCÍA, J.D., 1998: «La necrópolis tardorromana del Molino. Paganismo y cristianismo en un mismo espacio cementerial», Memorias de Arqueología, 13, 171-210.

HIRST, S.M., WALSH, D.A. y WRIGHT, S.M., 1983: Bordesleyabey II: second report on excavations at Bordesleyabey, Redditch, Hereford-Worcestershire. BAR British Series, 11, London.

HUNOT, J.Y., 1996: «Les cercueils de bois médiévaux et modernes en Anjou: meubles précieux ou simples caisses?», Revue archéologique de l'ouest, 13, 185-203.

INIESTA SANMARTÍN, A. y MARTÍNEZ ALCALDE, M., 2000: «Nuevas excavaciones en la necrópolis tardorromana de la Molineta (Puerto de Mazarrón, Murcia)», Anales de Prehistoria y Arqueología, 16, 199-224.

JALUT, G., DEDOUBAT, J.J., FONTUGNE, M. y OTTO, TH., 2009: «Holocene circum-Mediterranean vegetation changes: Climate forcing and human impact», Quaternary International, 200, 4-18.

JALUT, G., ESTEBAN, A., BONNET, L., GAUQUELIN, T. y FONTUGNE, M., 2000: «Holocene climatic changes in the western Mediterranean, from southeast France to south-east Spain», Palaeogeography, Palaeoclimatology, Palaeoecology, 160, 255-290.

KEEPAX, C. A., 1975: «Scanning electron microscopy of wood replaced by iron corrosion products», Journal of Archaeological Science, 2, 145-50.

KEEPAX, C. A., 1989: «Corrosion 'preserved wood': advances since 1975», en R. JANAWAY y B. SCOTT (Eds.), Guidelines for dealing with material from sites where organic remains have been preserved by metal corrosion products: proceedings of a joint conference between UKIC Archaeology Section and the Council for British Archaeology Science Committee, Leeds 1983 , Occasional Papers, 8, The United Kingdom Institute for Conservation, 15-20, London.

LÓPEZ GONZÁLEZ, G., 2001: Los árboles y arbustos de la Península Ibérica e Islas Baleares (Especies silvestres y las principales cultivadas), Madrid-Barcelona-México.

MACHADO YANES, M.C., JOVER MAESTRE, F. J. y LÓPEZ PADILLA, J. A., 2004: «Primeras aportaciones antracológicas del yacimiento de Terlinques (Villena, Alicante)», en L. HERNÁNDEZ ALCARAZ y M. S. HERNÁNDEZ PÉREZ (Eds.), La Edad del Bronce en tierras valencianas y zonas limitrofes, 363-368, Alicante.

MACHADO YANES, M.C., JOVER MAESTRE, F.J. y LÓPEZ PADILLA, J.A., 2009: "Antracología y paleoecología en el cuadrante suroriental de la Península Ibérica: las aportaciones del yacimiento de la Edad del Bronce de Terlinques (Villena, Alicante)», Trabajos de Prehistoria, 66 (1), 75-97.

MASPERO, A., 1989: «La necropoli Longobardi di Trezzosull'Ada, i repartilignei», en S. LUSUADI
SIENA (A curadi), L'eredital Longobarda ritrovamenti archeologici nei milanese e nelleterredell'Adda.

MATTERNE, V., 2001: Agriculture et alimentation végétale durant l'âge du Fer et l'époque gallo-romaine en France septentrionale, Montagnac.

MOSKAL, M. y BADAL, E., 2008: «Análisis e identificación de objetos orgánicos de la necrópolis de la Edad del Bronce de Opatów (Polonia)», en S. ROVIRA LLORENS, M. GARCÍA-HERAS, M. GENER MORET y I. MONTERO RUIZ (Eds.), Actas VII Congreso Ibérico de Arqueometría, Madrid, 8-10 octubre de 2007, 136143, Madrid.

PANTALEÓN-CANO, J. YLL, E. I., PÉREZ-OBIOL, R. y ROURE, J. M., 2003: «Palynological evidence for vegetational history in semi-arid areas of the western Mediterranean (Almería, Spain)», The Holocene,13(1), 109-119.

PÉTREQUIN, A.M., BAUDAIS-LUNDSTRÖM, K., REYNAUD, C., PARISOT, J.P., ODOUZE, J.L., MONNIER, J.L., GAILLARD DE SÉMAINVILLE, H., FOURNIER, G., CHABEUF, M., CASTEL, B., PÉTREQUIN, P. y CHAIX, L., 1980: «Le site funéraire de Soyria à Clairvaux-les-Lacs (Jura), Revue Archéologique de l'Est et du Centre-Est, 31, 157-230.

PIQUÉ, R., 2006: «Los carbones y las maderas de contextos arqueológicos y el paleoambiente», Ecosistemas, 2006/1, http://revistaecosistemas.net/pdfs/407.pdf.

RIPOLL LÓPEZ, G., 1998: Toreútica de la Bética (siglos VI y VII d.C), Barcelona.

RODRÍGUEZ-ARIZA, M. O., 1992: Las relaciones hombre-vegetación en el Sureste de la Península Ibérica durante las Edades del Cobre y Bronce a partir del análisis antracológico de siete yacimientos arqueológicos. Tesis doctoral, Universidad de Granada.

RODRÍGUEZ-ARIZA, M. O., 2008: «The use of wood in Argaric settlements of the south-eastern Iberian Peninsula», en F. DAMBLON y M. COURT-PICON (Coords.): 4th International Meeting of Anthracology. Programme and Abstracts. Geological Survey of Belgium Professional Papers, 303, 123.

RODRÍGUEZ-ARIZA, M.O. y MONTES MOYA, E., 2010: «Paisaje y gestión de los recursos vegetales en el yacimiento romano de Gabia (Granada) a través de la arqueobotánica», Archivo Español de Arqueología, 83, 85-107.

RODRÍGUEZ-ARIZA, M. O., FRESNEDA PADILLA, E., PEÑA RODRÍGUEZ, J. M. y LÓPEZ LÓPEZ, M., 1999: «Los niveles ibéricos de Fuente Amarga (Galera, Granada)», en XXIV Congreso Nacional de Arqueología: Cartagena 1997, 283-288, Murcia.

ROLLIER, G., 1992: «Découverte d'une sépulture remarquable dans les fouilles du narthex de l'église du monastère de Cluny», en Les veines du temps: lectures du bois en Bourgogne, 347-349, Autin.

ROS SALA, M. M., CARRIÓN GARCÍA, J. S., NAVARRO HERVÁS, F., RODRÍGUEZ ESTRELLA, T., GARCÍA MARTÍNEZ, M. S., PRECIOSO ARÉVALO, M. L., PORTÍ DURÁN, M. E., DE MIGUEL IBÁÑEZ, M. P., MEDINA RUIZ, SÁNCHEZ 
GONZÁlEZ, M. J., GÓMEZ CARRASCO, J. G., ATENZA JUÁREZ, G. y CASTILLA WANDOSELL, A., 2008: «Estudio integral del yacimiento Punta de los Gavilanes (Puerto de Mazarrón, Murcia) y su entorno inmediato: Proyecto Gavilanes 2007», en M. LECHUGA GALINDO, P. E. COLLADO ESPEJO y M. B. SÁNCHEZ GONZÁLEZ, (Coords.), XIX Jornadas de Patrimonio Cultural de la Región de Murcia: Cartagena, Alhama de Murcia, La Unión y Murcia, 7 de octubre al 4 de noviembre 2008, 57-62, Murcia.

SALIN, C., 1952: La civilisation mérovingienne d'après les sépultures, les textes et le laboratoire, deuxième partie: les sépultures, Paris.

SCHWEINGRÜBER, F. H., 1978: MikroskopischeHolzanatomie. Anatomiemicroscopique du bois. Microscopic wood anatomy, Swiss Federal Institute for Forest, Snow and Landscape Research, Birmensdorf.

SCHWEINGRÜBER, F. H.,1990: AnatomieeuropäischerHölzerein Atlas zurBestimmungeuropäischer Baum-, Strauch-und Zwergstrauchhölzer Anatomy of European woods an atlas for the identification of European trees shrubs and dwarf shrubs, Stuttgart.

SOULIER, P., 1988: Histoire et archéologie à l'abbaye de Maubuisson. Cergy-Pontoise, Conseil Général du Val d'Oise.

STIKA, H.P., 1988: «BotanischeUntersuchungen in der BronzezeitlichenHöhensiedlungFuenteÁlamo», Madrider Mitteilungen, 29, 21-76.

VERNET, J.-L., OGEREAU, P., FIGUEIRAL, I., MACHADO, C. y UZQUIANO, P., 2001: Guide d'identification des charbons de bois préhistoriques et récents. Sud-Ouest de l'Europe: France, Péninsule Ibérique et îles Canaries, Paris.

VIZCAÍNO SÁNCHEZ, J., 2007: La presencia bizantina en "Hispania » (siglos VI-VII): la documentación arqueológica. Antigüedad y Cristianismo, XXIV.

WATSON, J., 1988: «The identification of organic materials preserved by metal products», en S.L. OLSEN (Ed.), Scanning electron microscopy in archaeology, BAR International Series 452, 65-76, Oxford. 